\title{
Notes
}

\section{Synthesis, Spectroscopic and Ligand Field Properties of trans-Difluorobis(2,2-dimethylpropane-1,3-diamine)chromium(III) Perchlorate}

\author{
Jong-Ha Choi, ${ }^{*}$ Keon Sang Ryoo, and Sang Hak Lee ${ }^{\dagger}$ \\ Department of Chemistry, Andong National University, Andong 760-749, Korea. ${ }^{*}$ E-mail: jhchoi@andong.ac.kr \\ 'Department of Chemistry, Kyungpook National University, Daegu 702-701, Korea \\ Received August 28, 2010, Accepted October 24, 2010
}

Key Words: Difluoro, Bidentate $\mathrm{Me}_{2}$ tn, Chromium(III), Electronic spectrum, AOM parameter

The preparation and characterization of novel chromium(III) complexes have received much attention because the chromium(III) materials are promising materials for tunable solid state laser in the spectral region between 600 and $1100 \mathrm{~nm} .{ }^{1}$ As a prerequisite for these applications, a detailed study of the spectroscopic and ligand field properties is needed. Furthermore, the geometrical and conformational isomerism in transition metal complexes has been an area of intense activity and has provided much basic structural information. ${ }^{2}$ The 2,2-dimethylpropane-1,3-diamine ( $\left.\mathrm{Me}_{2} \mathrm{tn}\right)$ as a bidentate ligand can coordinate to a central metal ion forming a six-membered ring, and the spectroscopic properties of the resulting metal complexes can be compared with those of the corresponding complexes containing the unsubstituted tn diamine system. ${ }^{3}$

The preparation, spectroscopic properties and crystal structures of the series diacidochromium(III) complex containing $\mathrm{Me}_{2} \mathrm{tn}$ as a bidentate ligand have been reported extensively. ${ }^{4-8}$ The $\left[\mathrm{Cr}\left(\mathrm{Me} \mathrm{tn}_{2} \mathrm{~L}_{2}\right]^{+}(\mathrm{L}=\right.$ monodenate $)$ cation can exist as trans and cis geometric isomers. In addition, there are two possible conformations with respect to the six-membered rings in the trans isomer. The carbon atoms of the two chelate rings of the $\mathrm{Me}_{2}$ tn ligands can be located on the same side (syn conformer) or on opposite side (anti conformer) of the equatorial plane. In the case of trans- $\left[\mathrm{Cr}\left(\mathrm{Me}_{2} \mathrm{tn}_{2}\right)_{2} \mathrm{Br}_{2}\right]_{2} \mathrm{Br}_{2} \cdot \mathrm{HClO}_{4} \cdot \mathrm{H}_{2} \mathrm{O}$ and trans$\left[\mathrm{Cr}\left(\mathrm{Me}_{2} \mathrm{tn}\right)_{2} \mathrm{Cl}_{2}\right] \mathrm{Cl}$, independent syn and anti conformational isomers were found within the crystal lattice ${ }^{4,5}$ while structural analyses of trans-[Cr( $\left.\left.\mathrm{Me}_{2} \mathrm{tn}\right)_{2}(\mathrm{NCS})_{2}\right] \mathrm{NCS} \cdot 1 / 2 \mathrm{H}_{2} \mathrm{O}$, trans$\left[\mathrm{Cr}\left(\mathrm{Me}_{2} \mathrm{tn}\right)_{2} \mathrm{Cl}_{2}\right] \mathrm{ClO}_{4}$ and trans- $\left[\mathrm{Cr}\left(\mathrm{Me}_{2} \mathrm{tn}\right)_{2} \mathrm{Cl}_{2}\right]_{2} \mathrm{ZnCl}_{4}$ indicated that two chelate rings of $\mathrm{Me}_{2}$ tn ligands are only in the anti chair-chair conformation. ${ }^{6-9}$ The different arrangements of the two six-membered chelate rings of $\mathrm{Me}_{2}$ tn ligands may be dependent on the packing forces and counter anions in the crystal structure. The infrared, electronic absorption and emission spectroscopic properties are useful in distinguishing the geometric isomers of chromium(III) complexes. In particular, sharpline electronic spectroscopy can be used to probe the inequivalent sites of chromium(III) complexes because the zero phonon line and its splitting are very sensitive to the exact bond angles around the metal ion. ${ }^{10}$

By refluxing trans- $\left[\mathrm{Cr}(\mathrm{py})_{4} \mathrm{~F}_{2}\right] \mathrm{ClO}_{4}$ with the 2,3,2-tet and 3,2,3-tet in 2-methoxyethanol, the stereochemistry is retentive.
However, in the case of 2,2,2-tet, a cis arrangement of the fluoro ligand reported to occur. The last fact suggests to us a trans to $c i s$ isomerization of strarting materials. ${ }^{11}$

In this paper, we report on the synthesis, spectroscopic and ligand field properties of newly prepared trans $-\left[\mathrm{Cr}\left(\mathrm{Me}_{2} \mathrm{tn}\right)_{2} \mathrm{~F}_{2}\right]$ $\mathrm{ClO}_{4}$. The geometric configuration of the complex is proposed on the basis of its electronic and infrared spectra.

Infrared spectroscopy is useful in assigning the configuration of cis and trans isomers of octahedral chromium(III) complexes. ${ }^{12-14}$ The FT-infrared spectrum is presented in Figure 1.

The absorption near $3438 \mathrm{~cm}^{-1}$ and broadness of the band indicate that there are hydrogen bonds in this complex. The infrared spectrum shows strong bands in the region 3250 $3100 \mathrm{~cm}^{-1}$ and $2960-2850 \mathrm{~cm}^{-1}$ due to the symmetric and antisymmetric $\mathrm{N}-\mathrm{H}$ and $\mathrm{C}-\mathrm{H}$ stretching modes, respectively. The four main absorptions in the $\mathrm{N}-\mathrm{H}$ and in the $\mathrm{C}-\mathrm{H}$ stretching regions are indicative of the trans configuration. The infrared absorption spectrum of trans isomer reveals a simpler pattern than that of the cis isomer. This pattern may be rationalized on the basis of the higher symmetry of the trans isomer. Particularly, the $\mathrm{NH}_{2}$ bending at approximately $1600 \mathrm{~cm}^{-1}$ and the $\mathrm{CH}_{2}$ rocking bands at $900-800 \mathrm{~cm}^{-1}$ can discriminate between two geometric isomers of $\mathrm{CrN}_{4} \mathrm{X}_{2}{ }^{\mathrm{n+}}$ typed complexes. ${ }^{12-14} \mathrm{The}$ absorption band in the $1500-1600 \mathrm{~cm}^{-1}$ region due to the asymmetric deformation mode of the $\mathrm{NH}_{2}$ group is split in the case

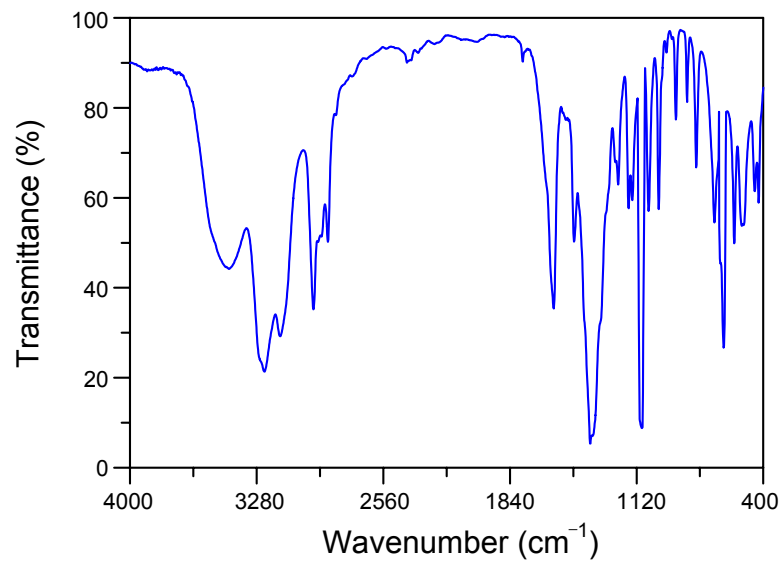

Figure 1. The mid-infrared spectrum of trans- $\left[\mathrm{Cr}\left(\mathrm{Me}_{2} \mathrm{tn}\right)_{2} \mathrm{~F}_{2}\right] \mathrm{ClO}_{4}$. 
of the cis isomer, while the trans isomer exhibits only a single band in this region. The one strong absorption band at $1591 \mathrm{~cm}^{-1}$ and the one medium band at $1475 \mathrm{~cm}^{-1}$ can be assigned to $\mathrm{NH}_{2}$ and $\mathrm{CH}_{2}$ bending modes. The $\mathrm{C}-\mathrm{N}$ stretching frequency occurs as a strong band at $1383 \mathrm{~cm}^{-1}$. The two absorptions at 1166 and $1144 \mathrm{~cm}^{-1}$, and two strong absorptions at 1051 and $994 \mathrm{~cm}^{-1}$ are due to the $\mathrm{NH}_{2}$ and $\mathrm{CH}_{2}$ twisting modes, respectively. The very strong absorptions at $1095 \mathrm{~cm}^{-1}$ and $626 \mathrm{~cm}^{-1}$ are due to the $v_{\mathrm{a}}(\mathrm{Cl}-\mathrm{O})$ stretching and $\delta_{\mathrm{d}}(\mathrm{OClO})$ bending modes of the perchlorate anion. The broadening or split of the perchlorate peaks results from the reduction in the symmetry of the $\mathrm{ClO}_{4}{ }^{-}$ ion to $C_{3 v}$ or $C_{2 v}$ due to its interaction with the amine hydrogen atoms and the formation of partial $\mathrm{H}$-bonding. A weak absorption at $940 \mathrm{~cm}^{-1}$ is also due to $v_{\mathrm{s}}(\mathrm{Cl}-\mathrm{O})$ stretching mode. The bands $v_{\mathrm{as}}\left(\mathrm{ClO}_{4}{ }^{-}\right)$and $\delta_{\mathrm{d}}\left(\mathrm{ClO}_{4}{ }^{-}\right)$of the perchlorate anion are not significantly affected by differing metal ions. ${ }^{14}$

It has been suggested that the cis isomer exhibits at least three bands in the $900-820 \mathrm{~cm}^{-1}$ region due to the $\mathrm{NH}_{2}$ rocking mode while the methylene vibration splits into two peaks in the $760-820 \mathrm{~cm}^{-1}$ region. However, the trans isomer shows two groups of bands, one band near $890 \mathrm{~cm}^{-1}$ arising from the amine vibration and a doublet near $800 \mathrm{~cm}^{-1}$ due mainly to the methylene vibration. The title complex exhibits two bands at 896 and $833 \mathrm{~cm}^{-1}$ in the $\mathrm{NH}_{2}$ rocking frequency region. The $\mathrm{CH}_{2}$ rocking bands at $781 \mathrm{~cm}^{-1}$ are observed.

Metal-ligand stretching bands occur in the far infrared range. There are also consistent differences between the infrared spectra of the cis and trans isomers of diacidobis(diamine) chromium(III) complexes in the region $560-400 \mathrm{~cm}^{-1}$. All the trans complexes show three bands in this region, whereas all the cis complexes show four strong bands. In the far-IR spectral range of trans- $\left[\mathrm{CrN}_{4} \mathrm{~F}_{2}\right]^{+}$complex with $D_{4 \mathrm{~h}}$ symmetry, group theory analysis predicts two $\mathrm{Cr}-\mathrm{N}$ and one $\mathrm{Cr}-\mathrm{F}$ infrared-active stretching vibrations, respectively. The one strong peak at 567 $\mathrm{cm}^{-1}$ can be assigned to the $\mathrm{Cr}-\mathrm{F}$ stretching mode by comparing the IR spectra of the corresponding dichloro, dibromo and diisothiocyanatobis(2,2-dimethylpropane-1,3-diamine)chromium(III) complexes which the bands are absent. ${ }^{5-7}$ The title complex shows a pattern of three bands: one strong band at $514 \mathrm{~cm}^{-1}$ and two other strong bands at 448 and $426 \mathrm{~cm}^{-1}$ due to the $\mathrm{Cr}-\mathrm{N}$ stretching modes. ${ }^{15}$ The infrared spectral properties

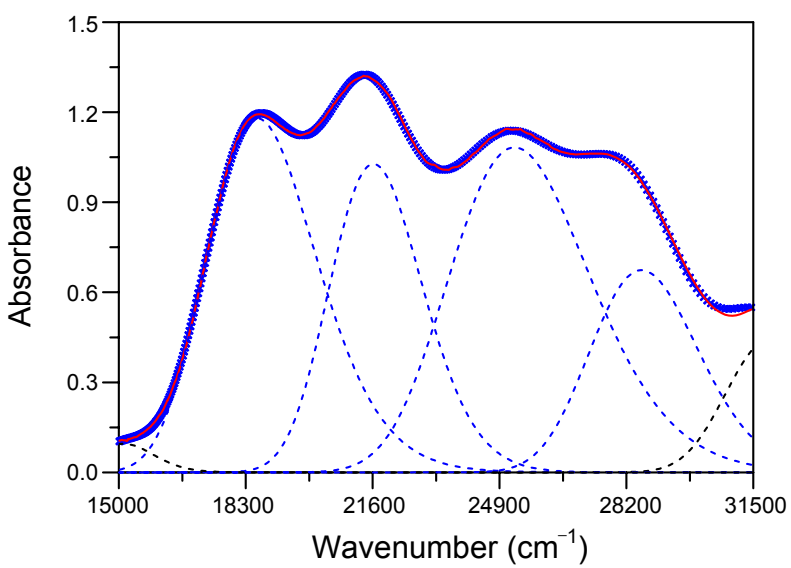

Figure 2. The visible absorption spectrum and its resolved overlapping peaks (dotted curves) of trans $-\left[\mathrm{Cr}\left(\mathrm{Me}_{2} \mathrm{tn}\right)_{2} \mathrm{~F}_{2}\right] \mathrm{ClO}_{4}$ in aqueous solution. of the novel complex would strongly support the assignment of trans configurational geometry.

The assignment of geometrical configuration is also suggested by inspection of the $\mathrm{d}$-d absorption spectra. ${ }^{16,17}$ The position of the spin-allowed transitions in the electronic spectra, the number of bands, and their coefficients are usually reliable indicators for distinguishing the $c i s$ and trans geometrical isomers. The more symmetrical trans chromium(III) complexes with two fluoro and $\mathrm{Me}_{2}$ tn ligands have four symmetric bands in the visible region, and these bands are located at higher wavelengths and have lower extinction coefficients than those of less symmetrical cis-isomers. The visible absorption spectrum (solid line) of $\left[\mathrm{Cr}\left(\mathrm{Me}_{2} \mathrm{tn}\right)_{2} \mathrm{~F}_{2}\right]^{+}$in aqueous solution at room temperature is represented in Figure 2.

The observation of four quartet bands in the $d$ - $d$ transition region is indicative of the trans configuration. In order to have some point of reference for the splitting and position of the bands, we have fitted the band profiles to four Gaussian curves, as seen in Figure 2. ${ }^{18}$ The contribution from outside bands was corrected for fine deconvolution. A deconvolution procedure on the experimental band pattern yielded maxima at 18600, 21620, 25290 and $28590 \mathrm{~cm}^{-1}$ for the noncubic $\left(D_{4 \mathrm{~h}}\right)$ split levels $\left({ }^{4} E_{\mathrm{g}}^{a}+\right.$ ${ }^{4} B_{2 g}$ and $\left.{ }^{4} A_{2 g}+{ }^{4} E_{g}^{b}\right)$ of ${ }^{4} T_{2 \mathrm{~g}}$ and ${ }^{4} T_{1 \mathrm{~g}}\left(O_{\mathrm{h}}\right)$, respectively. These band positions were used as the observed spin-allowed transition energies in the ligand field calculation.

In the framework of the angular overlap model the metalligand interactions are described in terms of localized bonding parameters of $\sigma$ - and $\pi$-type. Throughout the ligand field optimization, we assumed the tetragonal symmetry for the title complex. The parameters varied during the optimization were the interelectronic repulsion parameter $B$ plus the AOM parameters $\mathrm{e}_{\sigma}(\mathrm{F})$ and $e_{\pi}(\mathrm{F})$ for the fluoride-chromium, and $\mathrm{e}_{\sigma}(\mathrm{N})$ for the $\mathrm{Me}_{2}$ tn nitrogen-chromium. The $\pi$-interaction of the fluoride with the metal ion was considered to be isotropic. The $\pi$-interaction of amine nitrogens with $s p^{3}$ hybridization in the $\mathrm{Me}_{2}$ tn ligand was assumed to be negligible. However, it is noteworthy that the peptide nitrogen with $s p^{2}$ hybridization has a weak $\pi$ donor character. ${ }^{19}$ The Powell parallel subspace optimization procedure ${ }^{20}$ was used to find the global minimum. The results of the optimization and the parameter set used to generate the best-fit energies are listed in Table 1.

The following values were finally obtained for the ligand field parameters: $e_{\sigma}(\mathrm{N})=7175 ; e_{\sigma}(\mathrm{F})=7510 ; e_{\pi}(\mathrm{F})=1710$ and

Table 1. Observed band positions and calculated transition energies $\left(\mathrm{cm}^{-1}\right)$ in the electronic spectrum of trans- $\left[\mathrm{Cr}\left(\mathrm{Me}_{2} \mathrm{tn}\right)_{2} \mathrm{~F}_{2}\right]$

\begin{tabular}{ccc}
\hline Assignment & Observed $^{a}$ & Calculated $^{b}$ \\
\hline${ }^{4} B_{1 g} \rightarrow{ }^{4} E_{g}^{a}$ & 18600 & 18600 \\
${ }^{4} B_{1 g} \rightarrow{ }^{4} B_{2 g}$ & 21620 & 21619 \\
${ }^{4} B_{1 g} \rightarrow{ }^{4} A_{2 g}^{a}$ & 28590 & 28592 \\
${ }^{4} B_{1 g} \rightarrow{ }^{4} E_{g}^{b}$ & 25290 & 25289 \\
${ }^{4} B_{1 g} \rightarrow{ }^{4} A_{2 g}^{b}$ & $?$ & 40395 \\
${ }^{4} B_{1 g} \rightarrow{ }^{4} E_{g}^{c}$ & $?$ & 43275
\end{tabular}

${ }^{a}$ Obtained from the Gaussian component deconvolution, ${ }^{b} e_{\sigma}(\mathrm{N})=7175$; $e_{\sigma}(\mathrm{F})=7510 ; e_{\pi}(\mathrm{F})=1710 ; B=660 \mathrm{~cm}^{-1}$ 
Table 2. The AOM parameters $\left(\mathrm{cm}^{-1}\right)$ for trans- $\left[\mathrm{Cr}\left(\mathrm{Me}_{2} \mathrm{tn}_{2} \mathrm{~L}_{2}\right]^{+}\right.$

\begin{tabular}{cccccc}
\hline $\mathrm{L}$ & $e_{\sigma}\left(\mathrm{Me}_{2} \mathrm{tn}\right)$ & $e_{\pi}\left(\mathrm{Me}_{2} \mathrm{tn}\right)$ & $e_{\sigma}(\mathrm{L})$ & $e_{\pi}(\mathrm{L})$ & Ref \\
\hline $\mathrm{F}^{-}$ & 7175 & 0 & 7510 & 1710 & This work \\
$\mathrm{Cl}^{-}$ & 7358 & 0 & 5263 & 859 & 6 \\
$\mathrm{Br}^{-}$ & 7281 & 0 & 4983 & 946 & 5 \\
$\mathrm{NCS}^{-}$ & 7132 & 0 & 6160 & 32 & 7 \\
\hline
\end{tabular}

$B=660 \mathrm{~cm}^{-1}$. The AOM parameters are plausible and reproduce the spectrum pretty well. Table 2 contains the comparison of the AOM parameters with the values reported in the literature ${ }^{5-9}$ for the trans- $\left[\mathrm{Cr}\left(\mathrm{Me}_{2} \mathrm{tn}_{2} \mathrm{~L}_{2}\right]^{+}\right.$with anionic ligands. A ligand field analysis of absorption spectrum indicates that the fluoride is a strong $\sigma$ - and $\pi$-donor. The $e_{\sigma}(\mathrm{N})$ value of $7175 \mathrm{~cm}^{-1}$ for amine nitrogen of $\mathrm{Me}_{2} \mathrm{tn}$ is located in the normal range, and slightly smaller than other amine nitrogens. ${ }^{21}$ The strong coordination of two fluorine atoms to axial position may be caused a slight weakness of the $\mathrm{Cr}-\mathrm{N}\left(\mathrm{Me}_{2} \mathrm{tn}\right)$ bond strength in equatorial coordination plane. However, it is suggested that the four nitrogen atoms of the $\mathrm{Me}_{2} \mathrm{tn}$ ligand still have strong $\sigma$-donor properties toward chromium(III) ion. The value of Racah parameter, $B$ is about $72 \%$ of the value for a free chromium(III) ion in the gas phase. ${ }^{16}$ These factors plus AOM parameters can be used in determining the photolabilized ligand of the photoreaction in the chromium(III) complexes and predicting the relative efficiency of the $3 \mathrm{~d}-4 \mathrm{f}$ energy transfer in the heterometal dinuclear complexes. ${ }^{22,23}$

In conclusion, the infrared and electronic spectroscopic properties of the newly prepared complex show that the chromium atom is an octahedral environment, coordinated by two bidentate $\mathrm{Me}_{2}$ tn ligands and two fluorine atoms in trans positions. The ligand field analysis shows that the fluoride is strong $\sigma$ and $\pi$-donor and the nitrogen atoms of the $\mathrm{Me}_{2}$ tn ligand also have a strong $\sigma$-donor properties toward the chromium(III). Current studies in our laboratory on this compound indicate that the suitable crystals for X-ray analysis are not isolated until now. The mass spectrum, $2 \mathrm{D}\left[{ }^{1} \mathrm{H},{ }^{13} \mathrm{C}\right] \mathrm{HSQC}$ spectrum and crystal structural work including magnetic and conductance data will be reported later.

\section{Experimental Section}

The UV-visible absorption spectrum was recorded with a HP 8453 diode array spectrophotometer. The mid-infrared spectrum was obtained with a Mattson Infinities series FT-IR spectrometer using a $\mathrm{KBr}$ pellet. Analysis for $\mathrm{C}, \mathrm{H}$, and $\mathrm{N}$ was performed on a Carlo Erba 1108 Elemental Vario EL analyzer. The ligand field parameters were calculated using the AOMX program. ${ }^{24}$ The ligand, 2,2-dimethylpropane-1,3-diamine was purchased from Aldrich Chemical Company. All other chemicals were of reagent grade or better quality and used without further purification.

Caution! Although we have experienced no difficulty with the perchlorate salt of the complex described in this paper, this should be regarded as a potentially explosive compound and treated with care.

As starting material, trans $-\left[\mathrm{Cr}(\text { py })_{4} \mathrm{~F}_{2}\right] \mathrm{ClO}_{4}$ was prepared according to the literature. ${ }^{11}$ The complex trans- $\left[\mathrm{Cr}(\mathrm{py})_{4} \mathrm{~F}_{2}\right]$ $\mathrm{ClO}_{4}(1.0 \mathrm{~g})$ was dissolved in 2-methoxyethanol $(8 \mathrm{~mL}) .2,2-$ Dimethyl-1,3-propanediamine ( $0.4 \mathrm{~g})$ was added to this solution, which is then heated under reflux for $45 \mathrm{~min}$. The resulting red solution was concentrated and the residue was passed through a Sephadex G-10 column, eluting with water. The first band was blue, and the second band was red. The desired red fractions were combined, and freezing-dried to give the pink powder product. The compound was recrystallized three times for spectroscopic measurements from water. Anal. Found: C, $32.93 ; \mathrm{H}, 5.47 ; \mathrm{N}, 12.88 \%$. Calc. for $\mathrm{C}_{12} \mathrm{H}_{24} \mathrm{ClCrN}_{4} \mathrm{O}_{8}: \mathrm{C}, 32.77$; $\mathrm{H}, 5.50 ; \mathrm{N}, 12.74 \%$.

\section{References}

1. Powell, R. C. Physics of Solid-State Laser Materials; SpringerVerlag: New York, 1998.

2. Knight, P. D.; Scott, P. Coord. Chem. Rev. 2003, 242, 125.

3. House, D. A. Inorg. Chem. 1986, 25, 1671.

4. Choi, J. H.; Suzuki, T.; Kaizaki, S. Acta Cryst. 2002, C58, m539.

5. Choi, J. H.; Oh, I. G.; Lim, W. T.; Ryoo, K. S.; Kim, D. I.; Park, Y. C. Bull. Korean Chem. Soc. 2005, 26, 903.

6. Choi, J. H.; Clegg, W.; Nichol, G. S.; Lee, S. H.; Park, Y. C.; Habibi, M. H. Spectrochim. Acta 2007, 68A, 796.

7. Choi, J. H.; Lee, S. H. J. Mol. Struct. 2009, 932, 84.

8. Choi, J. H.; Lee, S. H.; Lee, U. Acta Cryst. 2008, E64, m1429.

9. Choi, J. H.; Joshi, T.; Spiccia, L. J. Chem. Cryst. 2010, submitted.

10. (a) Choi, J. H. Spectrochim. Acta 2000, 56A, 1653. (b) Choi, J. H. Chem. Phys. 2000, 256, 29. (c) Choi, J. H.; Park, Y. C. Bull. Korean Chem. Soc. 2003, 24, 384. (d) Choi, J. H.; Oh, I. G.; Linder, R.; Schönherr, T. Chem. Phys. 2004, 297, 7. (e) Choi, J. H.; Oh, I. G.; Suzuki, T.; Kaizaki, S. J. Mol. Struct. 2004, 694, 39. (f) Choi, J. H.; Choi, S. Y.; Hong, Y. P.; Ko, S. O.; Ryoo, K. S.; Lee, S. H.; Park, Y. C. Spectrochim. Acta 2008, 69A, 619.

11. Glerup, J.; Josephsen, J.; Michelsen, K.; E.; Pedersen, E.; Schäffer, C. E. Acta Chem. Scand. 1970, 24, 247.

12. Poon, C. K.; Pun, K. C. Inorg. Chem. 1980, 19, 568.

13. Nakamoto, K. Infrared and Raman Spectra of Inorganic and Coordination Compounds, 5th Ed.; John Wiley \& Sons: New York, 1997.

14. (a) Choi, J. H. Inorg. Chim. Acta 2009, 362, 4131. (b) Choi, J. H.; Clegg, W.; Harrington, R. W.; Lee, S. H. J. Chem. Cryst. 2010, 40,568 .

15. (a) Choi, J. H. Bull. Korean Chem. Soc. 1993, 14, 118. (b) Choi, J. H.; Oh, I. G. Bull. Korean Chem. Soc. 1993, 14, 348.

16. Lever, A. B. P. Inorganic Electronic Spectroscopy, 2nd Ed.; Elsevier: Amsterdam, 1984.

17. Choi, J. H.; Oh, I. G.; Ryoo, K. S.; Lim, W. T.; Park, Y. C.; Habibi, M. H. Spectrochim. Acta 2006, 65A, 1138.

18. GRAMS/32 V.5.21, Galactic Industries Corporation, Salem, NH 03079, USA.

19. (a) Choi, J. H.; Hoggard, P. E. Polyhedron 1992, 11, 2399. (b) Choi, J. H.; Hong, Y. P.; Park, Y. C. Spectrochim. Acta 2002, 58 A, 1599.

20. Kuester, J. L.; Mize, J. H. Optimization Techniques with Fortran; McGraw-Hill: New York, 1973.

21. (a) Choi, J. H. Bull. Korean Chem. Soc. 1994, 15, 145. (b) Choi, J. H. Bull. Korean Chem. Soc. 1997, 18, 819. (c) Choi, J. H. Bull. Korean Chem. Soc. 1999, 20, 81. (d) Choi, J. H. Bull. Korean Chem. Soc. 1998, 19, 575.

22. Vanquickenborne, L. G.; Ceulemans, A. Coord. Chem. Rev. 1983, $48,157$.

23. Subhan, Md. A.; Nakata, H.; Suzuki, T.; Choi, J. H.; Kaizaki, S. J. Lumin. 2003, 101, 307.

24. (a) Adamsky, H. AOMX program, Univ. of Düsseldorf, Germany, 1996. (b) Adamsky, H.; Schönherr, T.; Atanasov, M. Comprehensive Coordination Chemistry II, Elsevier Ltd, 2004, pp 661-664. 